\section{UTILIZACIÓN DE COMPONENTES NEUTROS DE CONSTRUCCIÓN EN LATINOAMÉRICA}

Julián Salas Serrano ${ }^{1}$, Aurelio Ferrero² y Patricia Lucas Alonso ${ }^{3}$

\section{Resumen}

En Latinoamérica la autoconstrucción es un hecho de gran extensión y diversidad, que en el caso del hábitat popular pierde su carácter de excepción para pasar a ser en algunos países vía mayoritaria de producción del hábitat. En la ejecución de estos alojamientos se emplean tecnologías tradicionales o adaptaciones de métodos y sistemas formales. Sin embargo, en opinión de los autores, podrían utilizarse tecnologías aun más apropiadas para este ámbito. Los componentes y productos no pueden ser independientes de los procesos.

Las necesidades de mejoramiento del hábitat popular explican el volumen constante, creciente y

\section{USAGE OF NEUTRAL ELEMENTS OF CONSTRUCTION IN LATIN AMERICA}

Julián Salas Serrano ${ }^{1}$, Aurelio Ferrero ${ }^{2}$ y Patricia Lucas Alonso ${ }^{3}$

\section{Abstract}

Self-help construction is a popular and diverse practice in Latin America. In the case of lowincome housing, in some countries self-help construction loses its condition of exception to become the main form of housing production. Different technologies or adaptations of formal procedures are used when building these units. However, the authors of this research pose that there are more suitable techniques that could be adopted. Components and products cannot work independently from processes.

The need for improvement of low-income housing explains the constant, growing and considerable 
muy considerable de la demanda de materias primas y de componentes neutros de construcción. Los propios usuarios señalan algunos de los requerimientos de estas tecnologías: materiales asequibles de poco peso y manejables. Por otra parte, existe una pléyade de microtalleres o gérmenes industriales locales con experiencia adquirida y vocación de crecer. Quizás sea el momento de señalar aportes válidos de entidades o de profesionales que partiendo de componentes neutros, tangibles y asequibles, mediante acoples o ensambles sencillos aportan soluciones tecnificadas, capaces de convertirse en prácticas de referencia para la construcción del hábitat popular en el entorno latinoamericano.

\section{PALABRAS CLAVE: LATINOAMÉRICA; COMPONENTES NEUTROS; HÁBITAT POPULAR; TECNOLOGÍAS COMPATIBLES; CONSTRUCCIÓN INCREMENTAL.}

Fecha de recepción: 30.05.12

Fecha de aceptación: 24.09.12

1 España. Dr. Ingeniero Industrial, Universidad Politécnica de Barcelona. Director de la Cátedra UNESCO de Habitabilidad Básica. Investigador del Instituto de Ciencias de la Construcción Eduardo Torroja CSIC-España. Email: julian.salas@ietcc.csic.es.

2 Argentina. Arquitecto. Investigador independiente del CONICET. Director del CEVE Centro Experimental de la Vivienda Económica.Email: direccion@ceve.org.ar.

3 España. Arquitecta y máster en proyectos arquitectónicos. Becaria JAE-Predoc del CSIC en el Instituto de Ciencias de la Construcción Eduardo Torroja. Email: patricialucas@ietcc.csic.es.

148 revista invi № 76 / Noviembre 2012 / Volumen No 27: 147-175 demand for raw materials and neutral construction materials. Users themselves point out some of the requirements of these technologies: materials that are affordable, lightweight and easy to handle. Moreover, there is a large number of local microworkshops or small productive centers attempting to make a step forward. This may be the time to acknowledge contributions from entities or individual professionals which through neutral, tangible and affordable elements, and by means of simple assemblies, provide highly technical solutions with the potential to become cornerstone practices for the construction of low-income housing in Latin America.

\section{KEYWORDS: LATIN AMERICA; NEUTRAL COMPONENTS; LOW-INCOME HOUSING; COMPATIBLE TECHNOLOGIES; INCREMENTAL CONSTRUCTION.}

Received: 30.05 .12

Accepted: 24.09.12

1 Spain. PhD. Industrial Engineer, Universidad Politécnica de Barcelona. Director, UNESCO Chair on Basic Livability. Rsearcher, Instituto de Ciencias de la Construcción Eduardo Torroja CSICEspaña. Email: julian.salas@ietcc.csic.es.

2 Argentina. Architect, CONICET Independent Researcher. Director, Centro Experimental de la Vivienda Económica CEVE. Email: dirección@ceve.org.ar.

3 Spain. Architect, MA in Architectural Projects. CSIC JAE-Predoc Fellow, Instituto de Ciencias de la Construcción Eduardo Torroja.Email: patricialucas@ietcc.csic.es. 


\section{Introducción: algunas formas de producción y gestión del hábitat popular latinoamericano}

En las ciudades latinoamericanas, una buena parte de la población, especialmente la que dispone de menos recursos, accede al hábitat urbano mediante procesos propios del sector informal. Villas autoproducidas ${ }^{4}$, asentamientos más o menos organizados, loteos o urbanizaciones irregulares dibujan un panorama en el que el acceso a la ciudad se produce por imperativo de la necesidad; una necesidad que no espera a las regulaciones, plazos o pagos del Estado, ni a la lógica que los mercados imponen para la organización del crecimiento urbano.

Como sostiene Abramo ${ }^{5}$, resulta factible detectar tres formas de acceso a la ciudad: la que sigue la lógica del mercado, la que se guía por la formalidad del sector público y la que obedece a una lógica impuesta por la necesidad: sector informal. En cada uno de estos tres ámbitos es posible detectar una serie de procedimientos distintos de gestión y construcción del hábitat (Tabla

4 En Argentina se denominan villas o villas de emergencia a los asentamientos informales que en España reciben la denominación de chabolas, en Perú pueblos jóvenes, ranchos en Venezuela, favelas en Brasil, limonás en Guatemala, tugurios en El Salvador, urbanizaciones piratas en Colombia, callampas en Chile, barbacoas en Cuba, ciudades paracaidistas en México.

5 Abramo, 2003
1). Los procedimientos legales de compra-venta abonan el mercado del suelo, los sistemas de adjudicación y subvención priman en las promociones del Estado y los procesos de toma de tierras ${ }^{6}$, ocupación o invasión son predominantes en el sector informal.

Los sistemas constructivos empleados en la producción formal de la ciudad son múltiples y variados, coincidiendo mayoritariamente en el hecho de contar con una asesoría técnica adecuada y por lo general ofrecer al comprador viviendas terminadas. En el caso de la promoción pública, la asesoría técnica sigue estando presente, aunque en algunas propuestas participativas se complementen con la colaboración de los propios usuarios. Según el programa o la iniciativa pública, es posible encontrar proyectos en los que se realizan viviendas completas y otros en los que se producen acciones parciales o de mejoramiento. Sin embargo, en la producción informal de la ciudad latinoamericana lo que predomina son acciones constructivas parciales respondiendo a lo que algunos llaman politicas no convencionales de vivienda. Se trata de operaciones de ampliación, remodelación o mejora, que en la mayoría de las ocasiones no cuentan con ningún tipo de asesoría técnica o control.

\footnotetext{
Salas, et al., 2010

7 Salas, et al., 2010; Ramírez, 2002; Fernández Wagner, 2004.
} 
La autoconstrucción funciona, por lo general, mediante etapas paulatinas, en ocasiones, muy dilatadas en el tiempo. Una vez realizado el asentamiento, por la toma de tierra o adquisición del terreno, se inicia un proceso productivo, extendido a lo largo de los años, que abarca de manera simultánea fases constructivas que en los procesos formales suelen producirse de manera lineal. No se trata de una simple prolongación de las etapas que se suceden en la construcción formal, sino que se produce una convivencia o solapamiento de diferentes fases. No es sólo que las construcciones se habiten antes de ser terminadas, sino que en ocasiones se construyen antes de contar con infraestructuras básicas, como agua, luz y alcantarillado. O se edifican antes de regularizar la situación legal y el régimen de propiedad de los terrenos, lo que ocasiona una serie de fenómenos que hacen compleja la gestión y producción de un hábitat que cumpla con unos requisitos mínimos de equipamiento. La resolución de los problemas que estos fenómenos plantean hace necesaria la intervención de un amplio y variado número de actores. Pensaren dar una respuesta que venga exclusivamente desde lo tecnológico es ilusorio, pues en muchos casos la cuestión constructiva es sólo un aspecto más, y no siempre el más importante, del complejo mosaico en el que interactúan problemas sociales, asuntos legales y urbanísticos, cuestiones de propiedad, planificación de infraestructuras, o problemas de gestión económica, política o ciudadana.

150 revista invi № 76 / Noviembre 2012 / Volumen № 27: 147-175
La importancia de lo tecnológico aparece así difusa entre una serie de factores que apuntan a la raíz económica, política y social de un problema cuya respuesta predominante no será una propuesta técnica, por novedosa que sea. Esto, sin embargo, no impide que sea posible pensar en qué tipo de proyectos arquitectónicos o de soluciones constructivas pueden ayudar a emprender o acortar el camino que proporcione soluciones habitables y transforme en verdaderos barrios los tejidos urbanos que están generando estos asentamientos. Unos tejidos que, por otra parte, se autoconstruyen de múltiples y variadas formas ${ }^{8}$ tanto desde el punto de vista del proceso, del producto, de las tecnologías empleadas o del marco socio-político en el que se realicen.

\section{Caracterización de tecnologías a base de componentes neutros presuntamente compatibles}

\section{LA ESCALA DEL POTENCIAL CAMPO DE ACTUACIÓN}

Diseccionar los problemas que se viven en los llamados asentamientos humanos ${ }^{9}$ es una tarea compleja, pues los casos son variados y se hacen necesarias

\footnotetext{
Salas, et al. 1988

Buthet, et al. 2007
} 
TABLA 1. TECNOLOGÍAS Y MECANISMOS DE GESTIÓN EN LOS DIFERENTES SECTORES DE PRODUCCIÓN DEL HÁBITAT.

\begin{tabular}{|c|c|c|}
\hline $\begin{array}{l}\text { DIFERENTES PRODUCTORES } \\
\text { DEL HÁBITAT }\end{array}$ & MECANISMOS DE GESTIÓN & TECNOLOGÍAS APLICADAS \\
\hline Sector de mercado (formal) & $\begin{array}{l}\text { Compra-venta mediante mecanis- } \\
\text { mos de mercado. }\end{array}$ & $\begin{array}{l}\text { Se ejecutan viviendas completas con control } \\
\text { técnico, aisladas o agrupadas. }\end{array}$ \\
\hline Sector público & $\begin{array}{l}\text { Subsidios, ayudas, programas } \\
\text { públicos... }\end{array}$ & $\begin{array}{l}\text { Se ejecutan unidades completas, generalmen- } \\
\text { te agrupadas, empleando tecnologías sencillas } \\
\text { de bajo coste o realizando programas de mejo- } \\
\text { ramiento progresivo con asesoría. }\end{array}$ \\
\hline Sector informal & $\begin{array}{l}\text { Tomas de tierra, compra-venta in- } \\
\text { formal, sitios o lotes con servicios, } \\
\text { microcréditos, programas de mejora } \\
\text { paulatina. }\end{array}$ & $\begin{array}{l}\text { Se autoconstruye, se realizan mejoras par- } \\
\text { ciales, generalmente de forma individual, y } \\
\text { en ocasiones, sin ningún tipo de asesoría o } \\
\text { control. }\end{array}$ \\
\hline Realizaciones híbridas & \multicolumn{2}{|c|}{$\begin{array}{l}\text { En numerosas ocasiones se producen iniciativas híbridas que toman formas de orga- } \\
\text { nización, gestión y tecnologías propias de varios sectores: sitios con servicios reali- } \\
\text { zados con mejora paulatina posterior. }\end{array}$} \\
\hline
\end{tabular}

Fuente: los autores

la participación, colaboración y propuestas de los propios vecinos. Por su extensión, el fenómeno de los asentamientos presenta un buen número de variedades en su gestión y situación habitacional. G. Rebord ${ }^{10}$ describe hasta ocho variantes en cuanto a la situación legal y la gestión de estos asentamientos más o menos organizados, entre los que pueden distinguirse desde villas autoproducidas hasta loteos irregulares o urbanizaciones autoconstruidas.

10 Rebord, 2010.
No obstante, y aun corriendo el riesgo de caer en una simplificación de la realidad, parece factible diferenciar tres escalas distintas a la hora de clasificar a grandes rasgos los problemas que afectan a los asentamientos informales (Tabla 2).

Moviéndonos en los ámbitos de lo urbanístico, lo habitacional y lo constructivo, parece posible detectar tres grandes grupos de asuntos: la planificación de las infraestructuras, el proyecto de las 
viviendas y las tecnologías empleadas en las diferentes fases de la construcción progresiva que, a lo largo del tiempo, van realizando los ocupantes de las viviendas. Se trataría de los procesos de construcción incremental en expresión de Cilento $^{11}$.

La distinción de estos tres ámbitos de actuación (Tabla 2) no deja de ser cuestionable, ya que en la mayor parte de los casos los problemas interactúan a varias escalas. Por poner un ejemplo, el problema legal hace en muchas ocasiones que no se planifiquen convenientemente los trazados de las infraestructuras públicas, o la falta de seguridad en la posesión de la tierra incide en la baja calidad constructiva con que se producen soluciones entendidas como cobijos temporales por sus moradores.

Sin embargo, sí parece posible pensar en los procesos de construcción a pequeña escala individual, pero con masividad dispersa, como un ámbito con características propias en el que puede ser útil aportar apoyos y/o soluciones técnicas para mejorar las condiciones de habitabilidad. Las tecnologías compatibles, a las que se refiere este trabajo, pretenden incidir en ese nivel, en el del completamiento, mejora y/o construcción progresiva.

Este ámbito, el de la vivienda progresiva, es un campo de actuación cuya escala de aplicación es más que considerable. Del ingente volumen de

11 Cilento, 2005.

152 revista invi № 76 / Noviembre 2012 / Volumen N ํ2: 147-175 necesidades de mejoramiento, ampliación y complementación que aqueja al hábitat latinoamericano hablan los datos recopilados por la CEPAL ${ }^{12}$, que pese al tiempo transcurrido, resultan una estimación del orden de \$171.486 millones de dólares (Tabla 3).

Pese a los quince años transcurridos desde el excelente trabajo elaborado por CEPAL para el HÁBITAT II (Estambul, 1996), los autores han estimado conveniente tomar en consideración estos datos (Tabla 3). El déficit habitacional no ha mermado desde entonces, de hecho hay constancia de que los procesos de tugurización se han multiplicado en Latinoamérica. Entre 1990 y 2000 este déficit habitacional aumentó de 38 a 52 millones de unidades. El porcentaje de viviendas que requieren mejoramientos, reparaciones o ampliaciones pasó del 54 al 61\%, mientras que la necesidad de nuevas unidades bajó del 46 al 39\% ${ }^{13}$. Estas estimaciones, realizadas por CEPAL en el 2006, hacen notar que el proceso no se ha frenado en valores absolutos, mientras que los precios unitarios por mejoramiento, ampliación y/o complementación se han incrementado sensiblemente en el período 1995-2012. Valgan pues los datos antes citados a modo de orientación fiable que, en cualquier caso, cuantifica el enorme volumen de este ámbito de producción del hábitat.

12 CEPAL, 1996.

13 CEPAL, 2006. 


\section{TABLA 2. TRES ESCALAS DE PROBLEMAS DE LOS ASENTAMIENTOS INFORMALES.}

\begin{tabular}{lll} 
ESCALA & PROBLEMAS & MECANISMOS \\
\hline Urbana & -Falta de acceso a las infraestructuras y servicios & -Gestión y planificación urbana. \\
& $\begin{array}{l}\text { públicos: agua, recogida de basuras, alcantarilla- } \\
\text { do, transporte público... }\end{array}$ & -Proyecto de las infraestructuras y servicios \\
& -Situaciones irregulares en los temas de propie- & urbanos. \\
& dad del suelo. & -Procesos de legalización de las parcelas. \\
\hline Habitacional & -Hacinamiento, falta de iluminación y ventilación & -El proyecto de lo habitacional: adecuación de con- \\
& adecuadas, incumplimiento de requisitos mínimos & junto, gestión de los espacios interiores, mejora de \\
& de confort ambiental... & las condiciones ambientales. \\
& -Escasa durabilidad y calidad de lo construido, & -Control técnico en la ejecución estructural. \\
& especialmente en zonas de riesgo: sismos, inun- & -Estrategias para el crecimiento de las viviendas: \\
& daciones, huracanes... & vivienda semilla ${ }^{14}$, vivienda galpón ${ }^{15}$. \\
\hline Tecnológica & -Empleo de sistemas poco eficientes. & -Sistemas constructivos compatibles con la am- \\
& -Incompatibilidad entre lo construido en distintas & pliación y la mejora progresiva. \\
& fases. & -Elementos o unidades de obra independientes, \\
& -Falta de control técnico. & cuya calidad pueda ser verificada. \\
\hline
\end{tabular}

Fuente: los autores

La escala del potencial campo de aplicación de estas tecnologías también salta a la vista en algunos programas de vivienda construidos en Latinoamérica. Aludimos a realizaciones fuera de la lógica que los autores propugnan en este trabajo, pero

14 Viviendas que parten de un núcleo básico y crecen hacia afuera.

15 Viviendas de altura libre interior muy superior a la de un piso, cuatro metros o más, que facilita el ulterior crecimiento y mejora por dentro. Se plantea una vivienda inicial de gran volumen, con doble o más altura, capaz de ir ganando estancias al separar distintos ámbitos dentro del espacio interior (González Lobo, 1999). que dada su escala e importancia, no pueden silenciarse. Son realizaciones masivas de millares de viviendas idénticas, prácticamente aprisionadas en parcelas minimas que impiden su crecimiento posterior. Se trata de conjuntos extremadamente 
TABLA 3. VALORACIÓN DE LAS ACCIONES DE MEJORAMIENTO*, AMPLIACIÓN** Y COMPLEMENTACIÓN*** REQUERIDAS PARA SALDAR EL DÉFICIT CUALITATIVO ACUMULADO (AÑO 1995) EN PAÍSES DE AMÉRICA LATINA Y EL CARIBE.

\begin{tabular}{lllll} 
PAíSES & \multicolumn{4}{l}{ VALOR ACCIONES DE REHABILITACIÓN (millones de dólares) } \\
& Mejoramiento & Ampliación & Complementación & \\
& A & B & C & D+B+C \\
\hline TOTAL & $\mathbf{2 8 . 8 6 9}$ & $\mathbf{4 9 . 2 6 8}$ & $\mathbf{9 3 . 3 4 9}$ & $\mathbf{1 7 1 . 4 8 6}$ \\
\hline Países Grupo I (de PIB>2000 U\$) & $\mathbf{1 8 . 1 5 2}$ & $\mathbf{3 9 . 7 8 9}$ & $\mathbf{7 8 . 5 6 9}$ & $\mathbf{1 3 6 . 5 1 0}$ \\
Puerto Rico & 10 & 39 & 79 & 128 \\
Argentina & 323 & 1.283 & 2.615 & 4221 \\
Venezuela & 103 & 700 & 1.427 & 2.230 \\
Uruguay & 19 & 132 & 269 & 420 \\
México & 3.363 & 8.661 & 17.288 & 29.312 \\
Chile & 174 & 1.184 & 2.414 & 3.772 \\
Brasil & 14.067 & 27.613 & 54.131 & 95.811 \\
Panamá & 90 & 177 & 346 & 613 \\
\hline Países Grupo II (PIB 1000 U\$-2000 U\$): & $\mathbf{8 . 2 3 3}$ & $\mathbf{6 . 1 5 7}$ & $\mathbf{1 1 . 6 0 0}$ & $\mathbf{2 5 . 9 9 0}$ \\
Cuba & 519 & 418 & 749 & 1.686 \\
Costa Rica & 31 & 25 & 44 & 100 \\
Paraguay & 859 & 692 & 1.240 & 2.791 \\
Jamaica & 144 & 116 & 208 & 468 \\
Colombia & 1.998 & 1.609 & 2.883 & 6.490 \\
Perú & 3.002 & 2.339 & 4.081 & 9.422 \\
Ecuador & 1.514 & 1.229 & 2.169 & 4.912 \\
El Salvador & 166 & 129 & 226 & 521 \\
\hline Países Grupo III (PIB<1000 U\$): & $\mathbf{2 . 4 8 4}$ & $\mathbf{2 . 9 2 3}$ & $\mathbf{3 . 1 8 0}$ & $\mathbf{8 . 5 8 7}$ \\
Guatemala & 654 & 638 & 764 & 2.056 \\
Rep. Dominicana & 263 & 300 & 437 & 1.000 \\
Bolivia & 414 & 511 & 519 & 1.444 \\
Honduras & 324 & 399 & 406 & 1.129 \\
Nicaragua & 265 & 344 & 337 & 946 \\
Haití & 564 & 731 & 717 & 2012 \\
\hline
\end{tabular}

(*) Por mejoramiento se entiende la construcción del suelo, compuesto de una base de hormigón y revestimiento vinílico y techo (estructura de cubierta y cobertura de placa de fibrocemento o similares).

(**) Por ampliación se entiende agregar un dormitorio a cada vivienda. El cálculo se aplicó al 75\% de las viviendas, pues se consideró que el 25\% de las viviendas incluidas en el déficit cualitativo no soportaban ampliación

$(* *)$ Por acciones de complementación se entiende la conexión de agua potable y alcantarillado intradomiciliario. Su valoración fue de $24,4 \%$ del valor de la vivienda.

Fuente: elaboración a partir de datos de CEPAL, sobre la base de informaciones oficiales y de MIDEPLAN de Chile (1995). 
FIGURA 1. VIVIENDAS REALIZADAS POR INFONAVIT, FONDO NACIONAL DE LA VIVIENDA DE LOS TRABAJADORES (MÉXICO), MEDIANTE UNOS ESCASOS MODELOS OUE SE REPITEN DE FORMA TRADICIONAL INALTERABLE, POR MILES, EN ITXAPALUCA, CAMINO DE PUEBLA (MÉXICO).

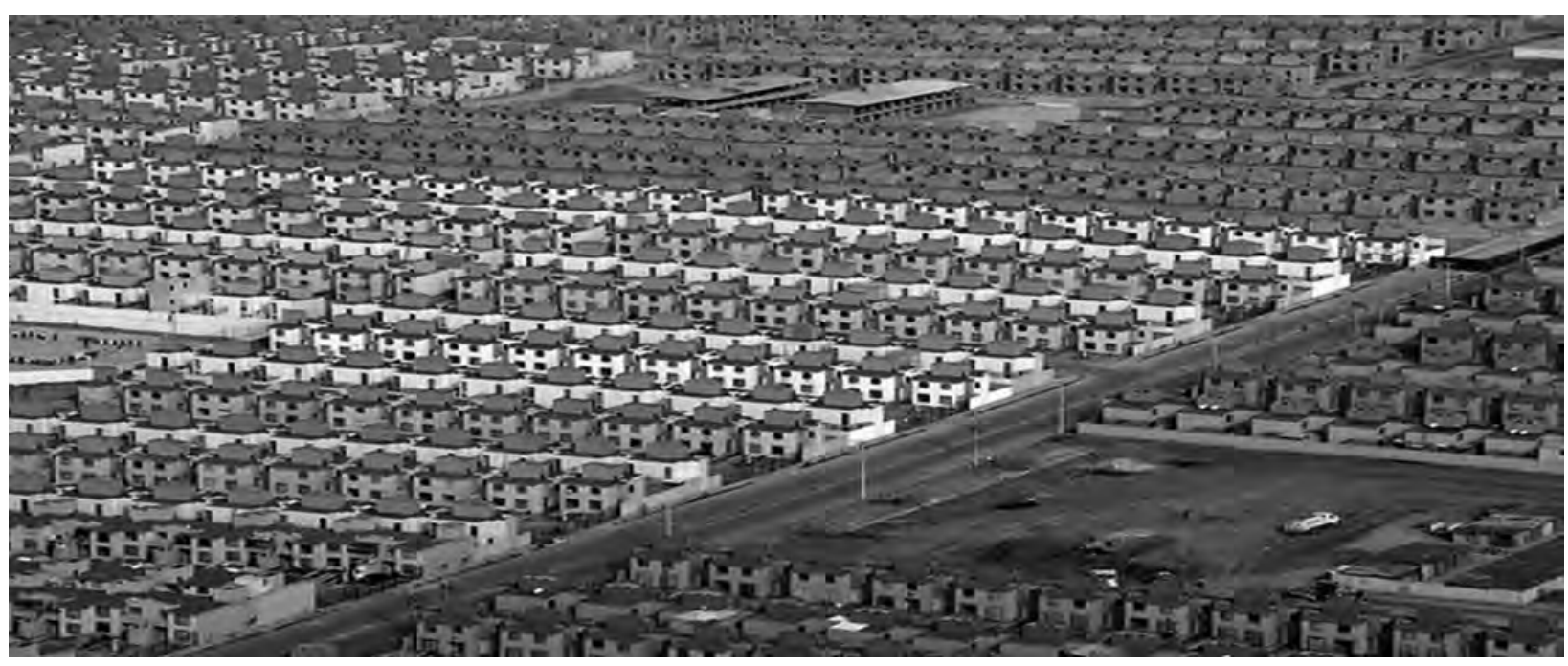

Fuente: INFONAVIT.

monótonos, formalmente en la línea de la antigua industrialización / prefabricación de la pasada reconstrucción europea, pero que en los casos de México (Figura 1), Brasil, Chile y hasta en El Salvador (Figura 2) se realizan en forma totalmente tradicional, mediante técnicas constructivas basadas en mano de obra barata y en busca del máximo beneficio económico. En estas realizaciones, la utilización de componentes neutros es muy escasa,

ARTíCULO: Utilización de componentes neutros de construcción en Latinoamérica / Julián Salas Serrano, Aurelio Ferrero y Patricia Lucas Alonso y no por inexistencia en el mercado del tipo de elementos que se propugnan.

Actualmente, en los países mencionados y en Latinoamérica en general, se detecta un importante desarrollo de la infraestructura productiva de elementos simples de construcción, desarrollo difuso, emplazado fundamentalmente en las grandes y dinámicas periferias urbanas. Se da en ellas una actividad creciente de construcción de vivienda ex 
FIGURA 2. VIVIENDAS REALIZADAS POR 'MAOUILADORAS' INSTALADAS EN LAS CERCANÍAS DEL AEROPUERTO DE SAN SALVADOR PARA Y POR SUS EMPLEADOS, TODAS IDÉNTICAS, CON LOS MISMOS MATERIALES, DE 36 M²$^{2}$, SIN POSIBILIDAD ALGUNA DE CRECIMIENTO, POR UN IMPORTE EQUIVALENTE A UNOS 100 SALARIOS MENSUALES DE LA ÉPOCA (2006).

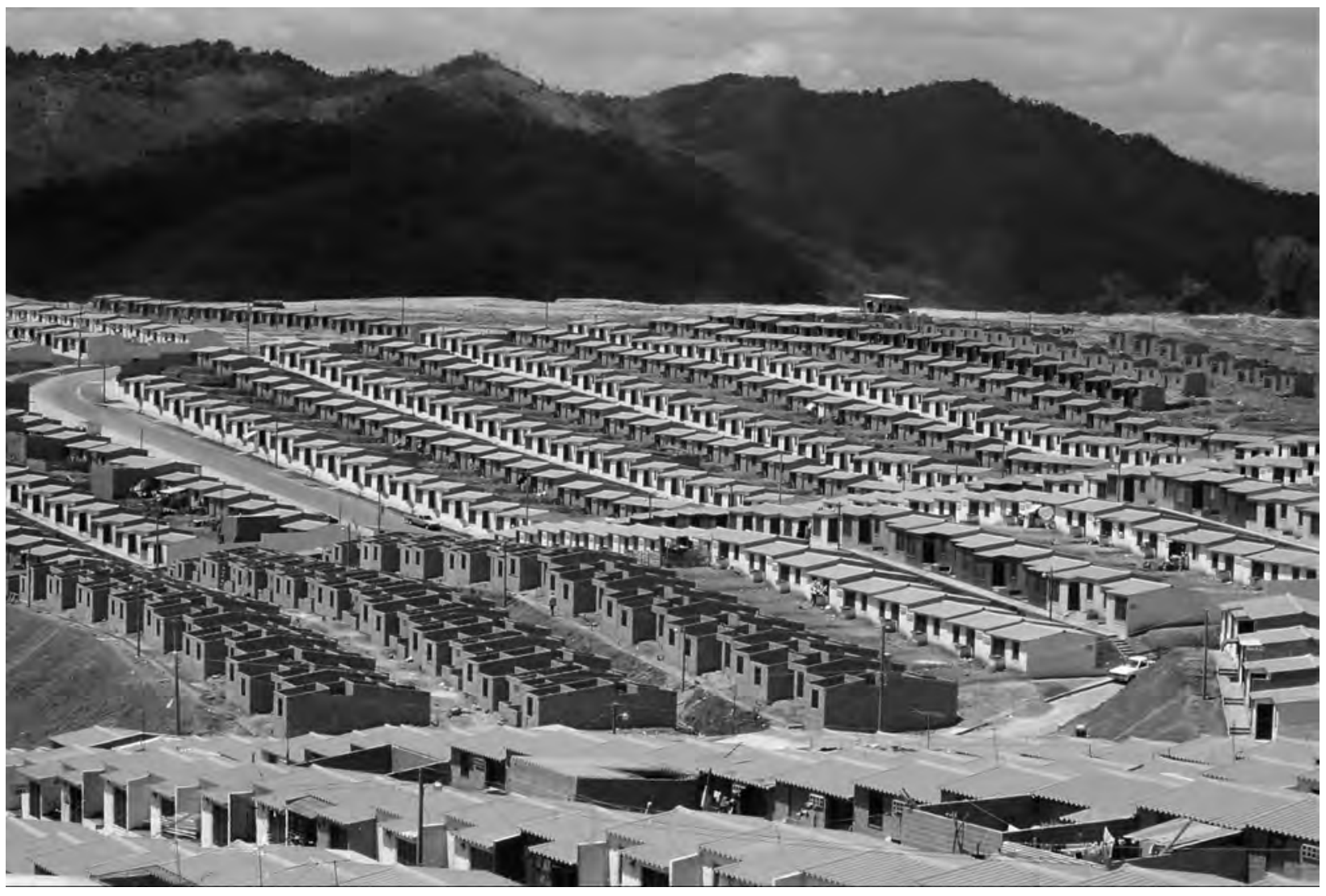

Foto: los autores 


\section{TABLA 4. LOS COMPONENTES NEUTROS EN LA CONSTRUCCIÓN DEL HÁBITAT POPULAR.}

\section{A: ¿QUÉ SON?}

Elementos tecnológicos autónomos y neutros: autónomos por su capacidad para ser elemento funcional que se materializa en una pieza tangible con vocación de compatibilidad; neutros por ser proyectados y realizados para que resulten utilizables en múltiples situaciones.

\section{B: ¿CÓMO FUNCIONAN?}

- Con autonomía estructural, de transporte y de manejo.

- Proporcionando compatibilidad con múltiples entornos constructivos.

- Necesitando pocos acabados posteriores y facilitando las operaciones de mantenimiento.

\section{C: ¿PARA QUÉ SE UTILIZAN?}

- Como respuesta tecnológica a variadas propuestas de gestión crediticia (microcréditos y otras modalidades).

- En construcción progresiva con elementos de características técnicas probadas.

- Para su empleo por micro-emprendedores: almacenes de suministros, constructores autónomos, bancos de materiales...

- Para facilitar la ruptura de la imagen uniforme, reconocible y en ocasiones estigmatizadora de las soluciones de vivienda social.

Fuente: los autores.

novo pero fundamentalmente de procesos de consolidación, crecimiento y mejora de asentamientos humanos informales ${ }^{16}$.

Los datos que siguen pretenden acotar este fenómeno. Se trata del resultado del análisis de 123 encuestas cumplimentadas por empresas e instituciones responsables de sistemas o subsistemas constructivos en las que se reseñaron tecnologías en uso en Latinoamérica, enmarcadas en el

16 Lorenzo, 2005.

ARTíCULO: Utilización de componentes neutros de construcción en Latinoamérica / Julián Salas Serrano, Aurelio Ferrero y Patricia Lucas Alonso
Programa CYTED ${ }^{17}$. La procedencia de las encuestas fue muy diversa y repartida entre 14 países latinoamericanos. El número de técnicas contabilizadas destinadas específicamente a vivienda fue de 113. De ellas, 89 se dedicaban únicamente a la construcción de viviendas unifamiliares.

Del total de las 123 técnicas catalogadas, 62 $(50,4 \%)$ abarcan todos o la mayor parte de los capítulos de obra de las viviendas; 40 (32,5\%) cubren varios componentes funcionales, principalmente

17 Salas, 2000.

revista invi ํำ 76 / Noviembre 2012 / Volumen N² 27: 147-175 157 
entrepisos, cubiertas o cerramientos exteriores e interiores; y $21(17,1 \%)$ sólo producen una tipología de componentes, tales como paneles ligeros para cerramientos interiores o viguetas y bovedillas para entrepisos.

Resulta destacable que casi la totalidad de las tecnologías (94\%) incorporan, en todo o en parte, la prefabricación de hormigón. El moldeo racionalizado en obra era bastante menos frecuente (29\%) y menos aún 'otros sistemas no tradicionales'. Estos últimos son, en general, técnicas novedosas, como morteros proyectados sobre mallas metálicas, cerramientos livianos de varias capas, etc. La construcción tradicional ocupa, en cambio, un lugar importante, participando en casi un 60\% de las técnicas catalogadas.

Al analizar los materiales utilizados prioritariamente por las distintas soluciones industrializadas (en ocasiones se señala más de un material), los resultados son mayoritarios para el hormigón (72\% de los casos), la madera (30\%), el acero (19\%), la albañilería (14\%), el ferrocemento o argamasa armada se señala en un $6 \%$ de los casos y otros materiales suponen un 54\%, entre los que se incluyen fibrocementos, plásticos o aceros especiales.

En cualquier caso, estos datos informan de la situación de distintos procesos industrializados o racionalizados frecuentes en el ámbito de la vivienda latinoamericana. Unidos a la acuciante necesidad de

158 revista invi № 76 / Noviembre 2012 / Volumen № 27: 147-175 mejora del hábitat popular, abren la posibilidad de pensar en estas opciones como posibles vías para la mejora de los asentamientos humanos.

\section{TECNOLOGÍA A BASE DE COMPONENTES NEUTROS: QUÉ, CÓMO Y PARA QUÉ}

La gama de nominaciones y clasificaciones que pretenden ser universales para matizar los grados o niveles de industrialización, y que son objeto de complejas nomenclaturas de aceptación multilate$\mathrm{ral}^{18}$ es muy extensa. Aún así, en consonancia con su importancia en el ámbito latinoamericano, ha parecido oportuno incluir la denominación específica de componentes neutros.

Se trata de elementos cuyos posibles usos como partes, incluso sustantivas de la obra, son conocidos, pero no se han diseñado ni producido para un empleo específico y concreto. Estos componentes pueden producirse mediante procesos elementales, o por el contrario, altamente industrializados. Aun a sabiendas de las dificultades que pueden introducir nuevas propuestas de léxico, se propone la denominación de componentes neutros por la necesidad de adjetivar como neutros los usos que se dan a estos componentes, y no a sus formas o funciones. En la Tabla 4 se ha plasmado un intento de responder, aún de forma imprecisa, a los contenidos de esta denominación, atendiendo a

18 Salas, 2000. 
tres cuestiones básicas: qué son, cómo funcionan y para qué se utilizan.

\section{TRES MATIZACIONES NECESARIAS:}

A: ¿Qué entender en este ámbito por componentes neutros y qué pueden aportar a la solución del problema de déficit habitacional? Podríamos acotarlos como aquellos elementos tecnológicos parciales, pero completos, proyectados, de manera que pueden resultar autónomos o agregables en múltiples situaciones.

Al calificarlos como parciales, la idea es que estas tecnologías no constituyen unidades de vivienda terminada. Al hablar de completos se apunta hacia la independencia de la pieza, que se piensa como un elemento prácticamente acabado, que no requiere una solución estructural previa o dependiente del entorno y que no necesita un tratamiento o acabado posterior a su puesta en obra.

No se propugna la idea de la industrialización presuntamente compatible, basada en el diseño de sofisticadas uniones con pretensiones de uso universal, sino más bien en el proyecto de elementos capaces de ensamblarse en múltiples entornos, ya que en la mayoría de los casos no han sido construidos pensando en su compatibilidad. La inmediatez de la unión, entre sí o con otros, resulta así un requisito importante. Como también lo es un cierto grado de autonomía, ya que las características técnicas del componente han de ser capaces de mantenerse en las variadas situaciones en que vaya a ser ensamblado.

B: ¿Cómo conseguir esto? Para lograr la independencia se hace necesario pensar en estos elementos como soluciones con autonomía estructural, de transporte y de manejo. Se hace preciso también pensar el elemento con cierta independencia con respecto a sus condiciones de borde. Y para conseguir su autonomía final, habría que considerar estas piezas como unidades acabadas, que no requieren tratamientos posteriores. Una vez ha sido instalada, la pieza debe requerir el menor número de acciones posibles para su acople y mantenimiento.

C: ¿Para qué pensar en este tipo de soluciones? ¿Qué ventajas tienen respecto a las soluciones de prototipo completo? Las respuestas tecnológicas suelen amoldarse mejor a los productos que a los procesos. Sin embargo, al hablar del hábitat de los asentamientos informales la gestión se hace protagonista. En este ámbito, los componentes neutros ayudan a dar respuestas tecnológicas a las propuestas de financiamientos parciales y puntuales o de microcréditos. La finalidad de estos programas no es tanto la de dotar al beneficiario de una vivienda completa, como la de colaborar en un proceso constructivo progresivo que, a través de las mejoras parciales, vaya consolidando los asentamientos y convirtiéndolos en barrios. 
Este tipo de propuestas se utilizan en proyectos de vivienda de nueva planta, algunos realizados en procesos participativos de ayuda mutua. Pero a la vez, y gracias fundamentalmente a la propuesta de gestión por microcréditos ${ }^{19}$, una buena parte de estas soluciones han sido empleadas también en los procesos de crecimiento y consolidación que llevan a cabo los habitantes de viviendas necesitadas de mejoras. Los componentes neutros vendrían a dar respuesta a una financiación de pequeña escala diferida a lo largo del tiempo.

Se trataría de ampliaciones, mejora de suelos, crecimiento de viviendas, techado de espacios, reposición de puertas y ventanas, instalación de equipamientos sanitarios o colocación de acabados. ¿Con qué tecnologías se puede responder a estas demandas? Las soluciones de albañilería tradicional, obviamente, son posibles en la mayor parte de los casos, pero las soluciones a base de componentes neutros brindan la posibilidad de construir con elementos realizados con un mayor control técnico.

Se trataría no sólo de asumir la progresividad del crecimiento habitacional y/o urbano, sino de realizar propuestas que cuenten con ella ${ }^{20}$. Estas estrategias, capaces de extender la acción social a un mayor número de beneficiarios, vendrían así a completar el trabajo de las políticas tradicionales

19 Bosío y García, 2007.

20 Ferrero y Basso, 2008.

160 revista invi № 76 / Noviembre 2012 / Volumen N ${ }^{0} 27$ : 147-175 de vivienda, que ejecutan unidades completas, pero siempre en un número más reducido.

A la hora de explicar por qué proyectar mejoras parciales y no unidades de vivienda completa habría sin duda que volver a referirse a la lógica de la necesidad, y entender los complejos y singulares procesos de financiación, así como las limitaciones de la economía familiar. Se trataría de un intento de extender los programas sociales al mayor número posible de habitantes, en vez de destinar todos los recursos a la construcción de un número insuficiente de viviendas que adjudicadas a unos, dejen a otros en la misma situación en la que estaban.

En estos ámbitos de construcción progresiva, las técnicas empleadas suelen ser en su mayor parte tradicionales. No obstante, el empleo de componentes neutros puede aportar ciertas mejoras, ya que, industrializados o racionalizados en cierta medida, pueden ser proyectados, examinados y probados como unidad, a pesar de su carácter fraccionario. Esto hace posible garantizar ciertos mínimos en su funcionamiento, unos mínimos que en el caso de construcciones realizadas con procedimientos tradicionales son mucho más difíciles de evaluar y que, generalmente, se comportan de manera trágica en los momentos de catástrofes naturales, inundaciones o sismos ${ }^{21}$.

21 Ferrero, 2003. 
Existe además otro factor que puede incidir a la hora de proponer estas soluciones, dado que al tratarse de un paso intermedio entre la construcción tradicional y las propuestas de industrialización más sofisticadas, pueden constituirse en tecnologías capaces de ser asimiladas por microemprendedores locales. Aparte de los beneficios que para la economía y el empleo puedan tener estas actividades, existe la posibilidad de convertir estos elementos constructivos en piezas comunes y reconocibles en la construcción de la zona, tanto en proyectos sociales como en otro tipo de construcciones.

El empleo de los componentes neutros en proyectos variados, no sólo como elementos de vivienda social, constituye sin duda un paso para eliminar la asociación directa que en muchos casos se hace entre ciertas tecnologías, proyectos o tipos de vivienda y los proyectos sociales. Esta asociación, en ocasiones termina por estigmatizar las soluciones más repetidas en este tipo de viviendas, que corren el riesgo de que se asimilen por una parte de la población, como soluciones o tecnologias para pobres y que por ello sean valoradas más por su imagen que por sus características técnicas reales.

\section{Procesos de producción de componentes neutros}

\section{MICROTALLERES PRODUCTIVOS O GÉRMENES INDUSTRIALES}

La realidad del sector productor de materiales y componentes de construcción en América Latina presenta una pléyade de pequeños talleres, unidades productivas, microempresas familiares, núcleos de producción de elementos... que, de manera genérica, proponemos denominar como gérmenes industriales ${ }^{22}$.

Se prefiere la expresión germen industrial frente a la de microtaller, por lo que implica de concepción dinámica. El aspecto micro no es lo esencial o característico de esta forma de producción. Por lo general, un micro taller no pretende ser micro a lo largo de toda su vida útil. El germen industrial, por contra, tiende a su consolidación, crecimiento e incluso multiplicación.

No hay razones para sostener que el pequeño taller conlleve o implique tecnología de segunda categoría. Es cierto que determinados procesos de producción (fabricación de perfilería de aluminio,

22 Salas, 2000. 
placas de fibrocemento, vidrio plano, cemento) requieren un tamaño crítico de producción muy superior al de estos talleres. Pero no lo es menos, que puede haber y de hecho los hay, en casos en los que se utiliza tecnología de buen nivel incorporada a equipos; por ejemplo, máquinas semiautomáticas para producir tubos de hormigón vibrocompactados, extrusadoras de viguetas pretensadas, sierras de corte de piedra para aplacados, equipos para ensamblar cerchas de madera, soldadura y plegado de placas ligeras de acero.

Estos núcleos productivos son la expresión más real hacia la que convergen dos tendencias en apariencia antagónicas, pero que en la práctica muestran una intensa capacidad generadora de soluciones. Se trata de la formalización de la informalidad y de la desmitificación de la industrialización importada, patentada o cerrada.

Al hablar de formalización de la informalidad, se alude a un conjunto de tendencias, programas y políticas, que pretenden generar puestos de trabajo rentables y nuevas formas organizativas y de producción de materiales, legalmente reconocidos, a partir de actividades ya existentes en el sector, aunque estas sean informales.

Por otra parte, la desmitificación de la industrialización es ya una tendencia incipiente que se plasma en distintas prácticas, como producción con equipos nacionales, utilización de materias primas autóctonas, eliminación de sofisticaciones importadas o

162 revista invi № 76 / Noviembre 2012 / Volumen № 27: 147-175 simplificación de procesos técnicos complejos. La desmitificación de la industrialización tiene ante sí un prometedor nicho tecnológico.

El germen industrial, entendido en sentido amplio, abarca desde la producción de materias primas y componentes hasta la prestación de servicios para la construcción y suele presentar la estructura propia de pequeña producción mercantil. Actúa mayoritariamente tratando de poner en el mercado materiales/componentes de construcción a menor costo que los de las grandes empresas, aunque en muchos casos con calidades, prestaciones y/o acabados inferiores y con frecuencia, incluso fuera de norma.

\section{DISEÑO, CONSTRUCCIÓN Y PRODUCCIÓN DEL HÁBITAT MEDIANTE EL EMPLEO INTENSIVO DE COMPONENTES NEUTROS}

El empleo intensivo de componentes neutros asequibles se vislumbra como una herramienta útil a la hora de abordar el problema del déficit habitacional. Pero a la vez, hace necesaria la implantación de una serie de criterios y recomendaciones que afectan al diseño, la construcción y la producción de la vivienda.

Resulta preciso establecer métodos y definiciones sobre el uso de materiales y componentes constructivos, sobre los sistemas de fabricación, montaje o ensamblado, así como tener en cuenta los mecanismos de adquisición. El empleo de este tipo de tecnologías va ligado al entendimiento del espacio

ARTíCULO: Utilización de componentes neutros de construcción en Latinoamérica / Julián Salas Serrano, Aurelio Ferrero y Patricia Lucas Alonso 
FIGURA 3. SISTEMA UNNE UNO, VÍCTOR PELLI (ARGENTINA).

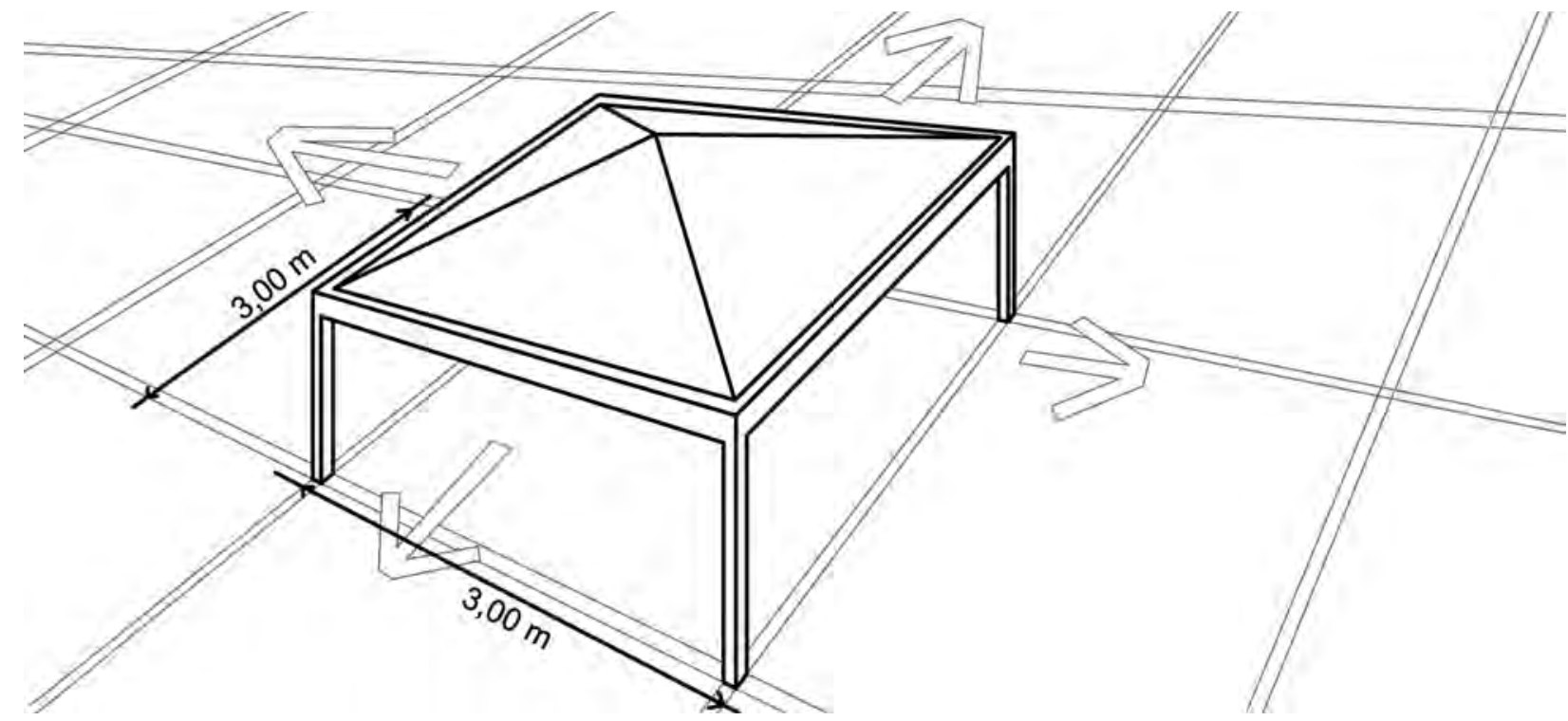

Fuente: Exposición 'Con y Sin Techo', Ministerio de Fomento de España y ASF, Madrid, 2012.

FIGURA 4. SISTEMA UMA DEL CEVE (CÓRDOBA-ARGENTINA): ELEMENTOS ELECTROSOLDADOS PRODUCIDOS Y REALIZACIÓN FINALIZADA A BASE DE CERRAMIENTO DE LADRILLO CERÁMICO.
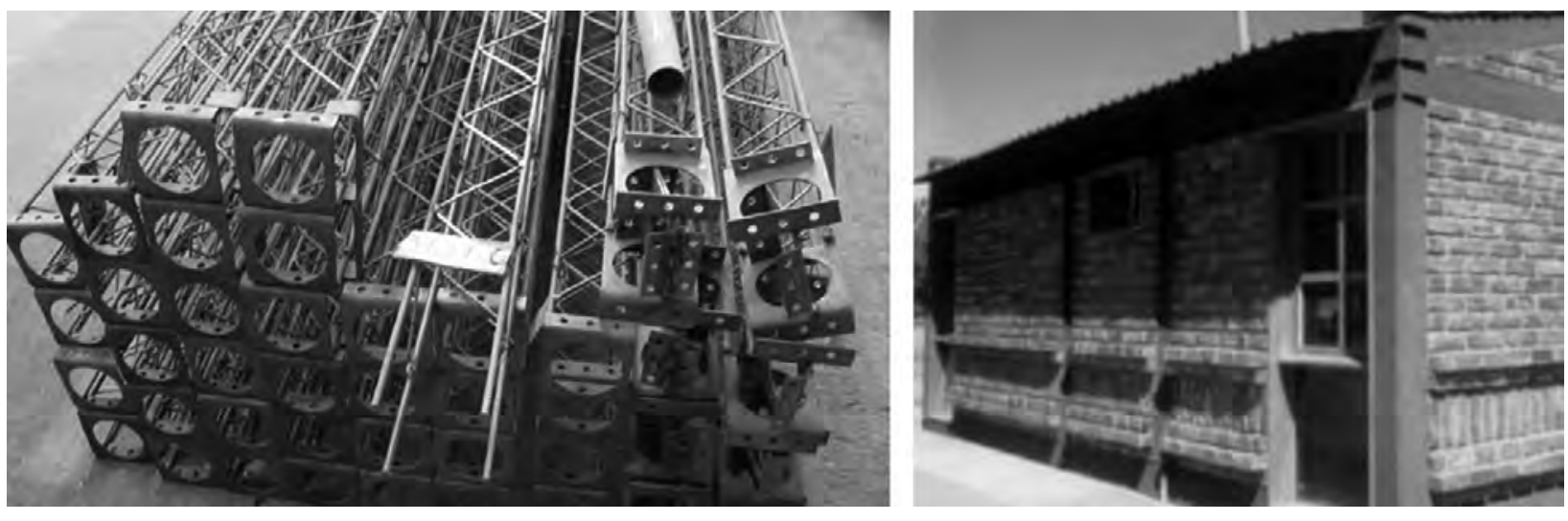

Fuente: CEVE 
FIGURA 5. VARIAS ETAPAS DE LA EJECUCIÓN DE 32 VIVIENDAS AUTOCONSTRUIDAS A BASE DE

QUINCHA MODULADA TRAS EL TERREMOTO DE 2006 EN ICA (PERÚ). PROYECTO Y DIRECCIÓN DE OBRA DE LA AROUITECTA MARIA EUGENIA LACARRA, PRIMER PREMIO DE LA XVI BIENAL DE AROUITECTURA PANAMERICANA (QUITO, 2007) SOBRE HÁBITAT SOCIAL Y DESARROLLO.
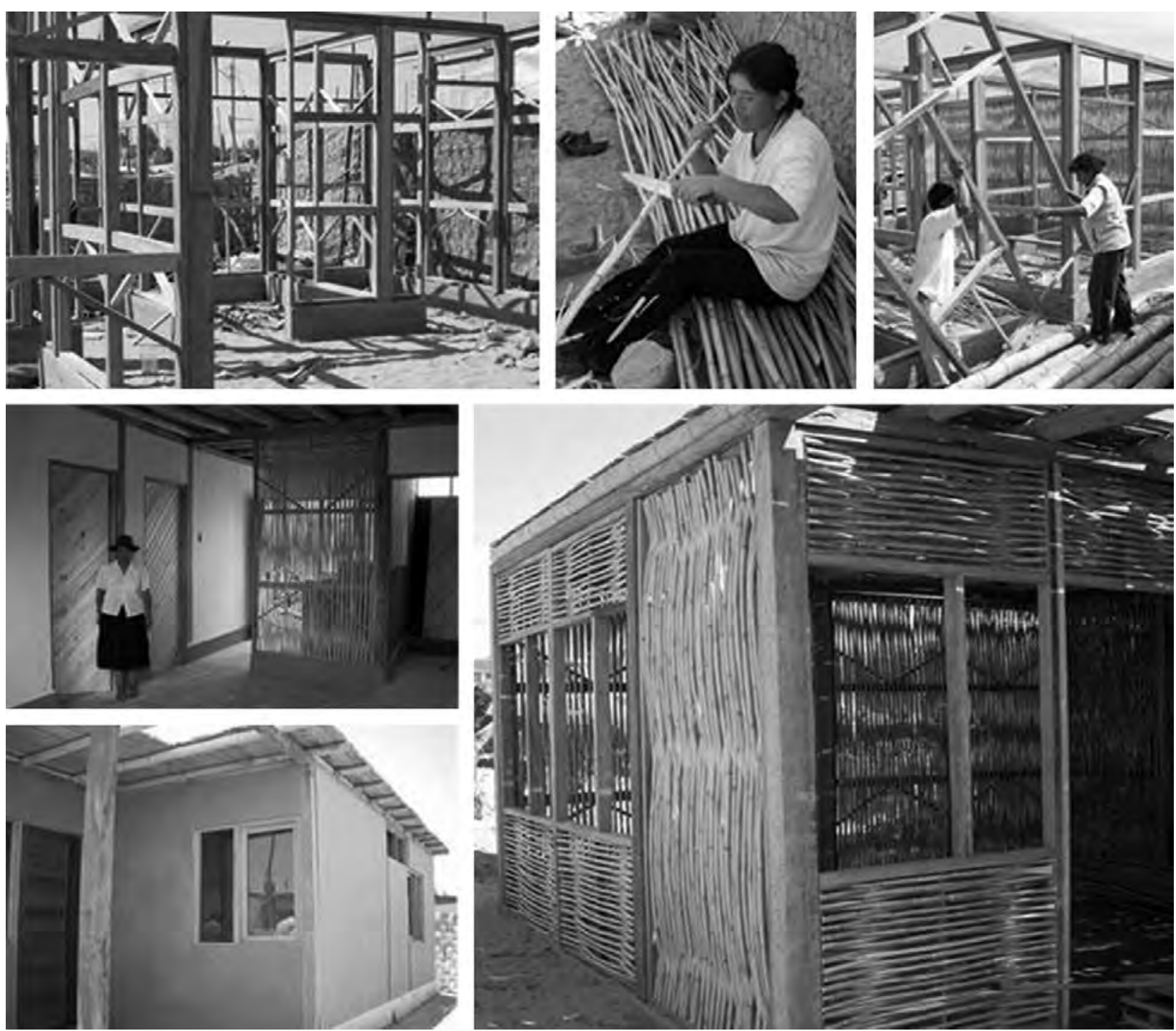

Fuente: María Eugenia Lacarra 


\section{TABLA 5. CRITERIOS Y RECOMENDACIONES PARA EL USO INTENSIVO DE COMPONENTES NEUTROS MEDIANTE}

SOLUCIONES TECNOLÓGICAS.

\section{CRITERIOS DE DISEÑO}

Soluciones tipológicas con modulaciones simples, preferentemente a base de módulos-objetos, en la búsqueda de un aspecto acorde con la cultura local, tanto en la expresión como en el manejo del espacio.

Promover el uso de tecnologías constructivas flexibles, combinables entre sí y que puedan incorporar los modos de vida, de producción, usos y costumbres de la población.

Garantizar condiciones mínimas de habitabilidad y durabilidad.

Favorecer, desde el diseño inicial, posteriores ampliaciones o modificaciones posibles, sin perder la calidad y la coherencia de las vinculaciones estructurales y constructivas.

Auspiciar el uso de tecnologías apropiables, que se adapten fácilmente a la cultura local de la comunidad que las recibe. DEFINICIÓN DE MATERIALES Y COMPONENTES CONSTRUCTIVOS

La adopción de tecnologías constructivas abiertas a una multiplicidad de formas productivas, favoreciendo la organización socio-productiva de las comunidades y contribuyendo a la generación de empleo.

Patrocinar el uso de tecnologías constructivas que incorporen fuerza de trabajo no calificada y favoreciendo la adopción de tecnologías que permitan la racionalización en el uso de los recursos financieros, y que faciliten implementar mecanismos simples de administración y gestión.

Promover la simplificación de mecanismos en la ejecución y el montaje, privilegiando la precisión y la eficacia estructural, utilizando equipos y herramientas de fácil operación y de bajo costo.

Promover el uso de materiales locales, aceptados culturalmente por las comunidades.

Prever los instrumentos técnicos comprensibles y adecuados (planos y pliegos de especificaciones entendibles por la comunidad) para facilitar el desarrollo progresivo de la vivienda.

\section{SISTEMAS DE FABRICACIÓN Y PRODUCCIÓN}

Promover el empoderamiento de sectores populares a través del fortalecimiento de su organización interna y su inserción en la producción de bienes y servicios.

Favorecer el empleo intensivo de mano de obra, evitando la adquisición de tecnologías importadas que generen la destrucción de puestos de trabajo locales y/o el pago en divisas.

Incluir la utilización de equipos, maquinarias y herramientas de fácil empleo y aprendizaje, de baja inversión y que no generen dependencia tecnológica.

Diseñar y propiciar la transferencia de tecnología implementando programas de asistencia técnica y capacitación, que además de incrementar los conocimientos técnicos específicos, tiendan a impulsar el desarrollo empresarial y promover su continuidad y fortalecimiento.

Favorecer a los proveedores locales, intentando retener los circuitos de capital en el ámbito regional y tendiendo a la dinamización de la economía del entorno.

Desarrollar e implementar tecnologías constructivas y de producción que no afecten negativamente al ambiente natural o construido.

Fuente: los autores 


\section{FIGURAS 6 Y 7. DOS EJEMPLOS EN LA COSTANERA DE YUCATÁN (MÉXICO).}

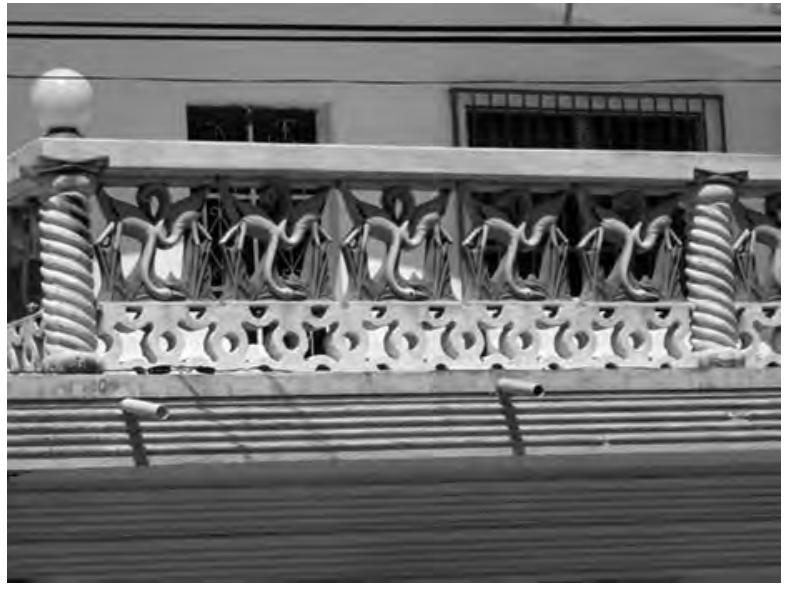

Fotos: los autores

construido como un proceso complejo en el que interviene no sólo lo tecnológico, sino también cuestiones económicas, de organización y gestión. Con respecto al diseño, habrá de tenerse en cuenta la interacción de todos los factores mencionados. Esto significa que no hay decisión en el proyecto que pueda despegarse de los materiales y su forma de obtención, así como de las tendencias o costumbres de formas espaciales anteriores. Por otra parte, los conceptos de flexibilidad y progresividad

166 revista invi № 76 / Noviembre 2012 / Volumen № 27: 147-175

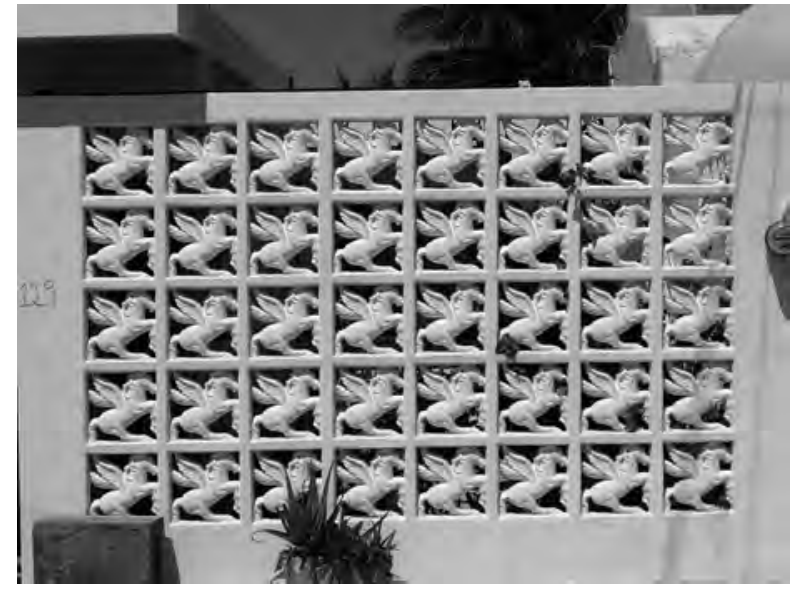

toman fuerza al hacerse evidente la necesidad de programar el proceso de evolución y transformación como una parte integral de la vivienda. De esta manera, un diseño planeado mínimamente deberá contemplar la flexibilidad para adaptarse a las diversas realidades locales y sociales y la progresividad $^{23}$ a la que estará sujeto con posterioridad a su situación inicial. El diseño apropiado de la vivienda ha de tener en cuenta su carácter intrínsecamente evolutivo ${ }^{24}$. El desafío será ofre-

23 Sepúlveda, de la Puente; Torres, y Muñoz, 1994.

24 Romero, 2006.

ARTÍCULO: Utilización de componentes neutros de construcción en Latinoamérica / Julián Salas Serrano, Aurelio Ferrero y Patricia Lucas Alonso 
cer alternativas que tomen en cuenta las variables involucradas en este proceso transformador.

Con la intención de favorecer desde el inicio de la vivienda las posteriores ampliaciones, se han realizado propuestas de estructuras vacías o esqueletos estructurales. Estos cumplirían la función de germen de vivienda o pie de casa, quedando como tarea a los pobladores el completamiento de sus cerramientos. Se aseguraría así la calidad estructural y constructiva, evitando que esta tarea se realice por mano de obra no calificada o poco experimentada. Con este sistema se ofrece un marco estable al que agregar las tecnologías compatibles. Las experiencias del arquitecto Víctor Pelli en Argentina, con el sistema UNNE UNO en los años sesenta (Figura 3), o la idea de la vivienda galpón del mexicano González Lobo ${ }^{25}$, así como los resultados probados de los procesos de investigación-acción del CEVE (Centro Experimental de la Vivienda Económica - Córdoba-Argentina) (Figura 4) ${ }^{26}$, podrían servir como ejemplos de este tipo de estrategias de diseño.

25 González Lobo, 1999.

26 El CEVE realiza investigación-acción, desarrollo tecnológico, transferencia y capacitación en el campo habitacional desde 1967. Su actividad es una referencia obligada en cuanto a procesos de mejoramiento y construcción social del hábitat popular latinoamericano. Durante su actividad ha desarrollado un buen número de componentes neutros, subsistemas y sistemas constructivos capaces de responder a los procesos de producción de hábitat social.
Este tipo de sistemas dejan la puerta abierta a la mejora y ampliación progresiva mediante componentes neutros. Una vez realizado el marco estructural, los propios usuarios pueden ir completando la vivienda a través de estos elementos. Encontrar estos componentes constructivos de pequeña escala en el mercado local, alimentado por la producción de los citados gérmenes industriales, ayudaría además a reforzar las economías propias.

La tecnología constructiva adoptada, nueva o existente, deberá favorecer la participación y la organización de los grupos sociales locales durante la etapa de gestión y ejecución habitacional. Y también, promover la incorporación de mano de obra no calificada, la capacitación y el uso de materiales tradicionales disponibles en el mercado inmediato. Muchos de estos elementos existen en realidad dentro de la producción actual del hábitat popular en Latinoamérica por lo que se trata de identificarlos, rescatarlos y potenciarlos, como en el caso de la quincha prefabricada (Figura 5). Partiendo de otro tipo de tecnologías y aun tratándose de usos 
FIGURA 8. LA VENTANA DE HORMIGÓN DEL CEVE (CÓRDOBA-ARGENTINA).
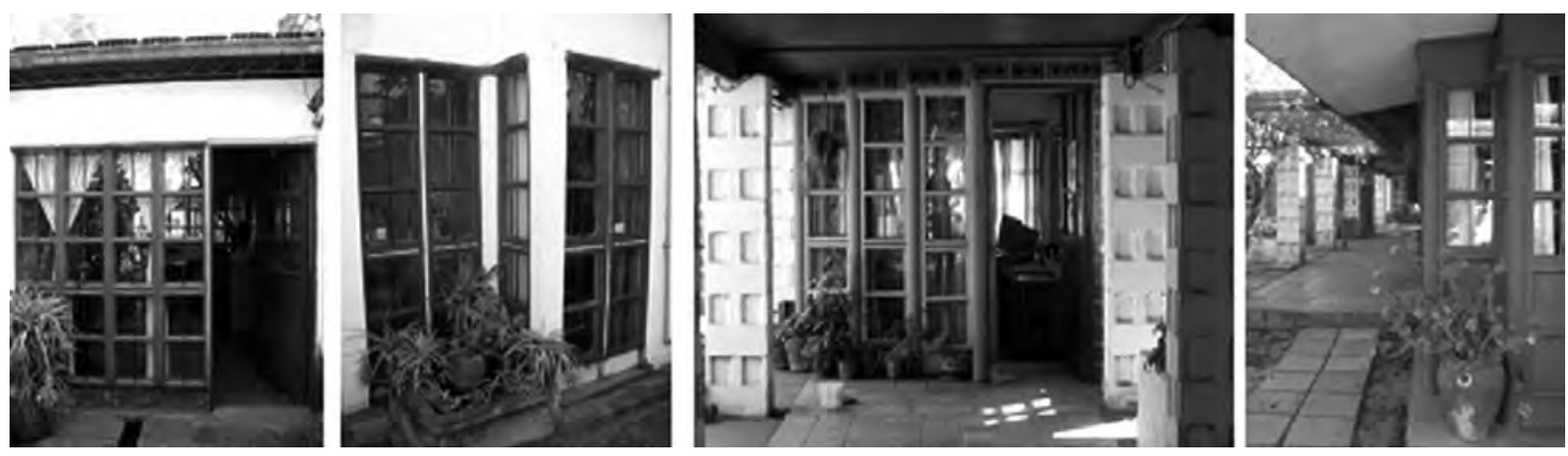

Fuente: CEVE. Fotos: los autores.

FIGURA 9. SANEAMIENTO URBANO, SALVADOR DE BAHÍA, JOÃO FILGUEIRAS LIMA, LELÉ (1980-82).
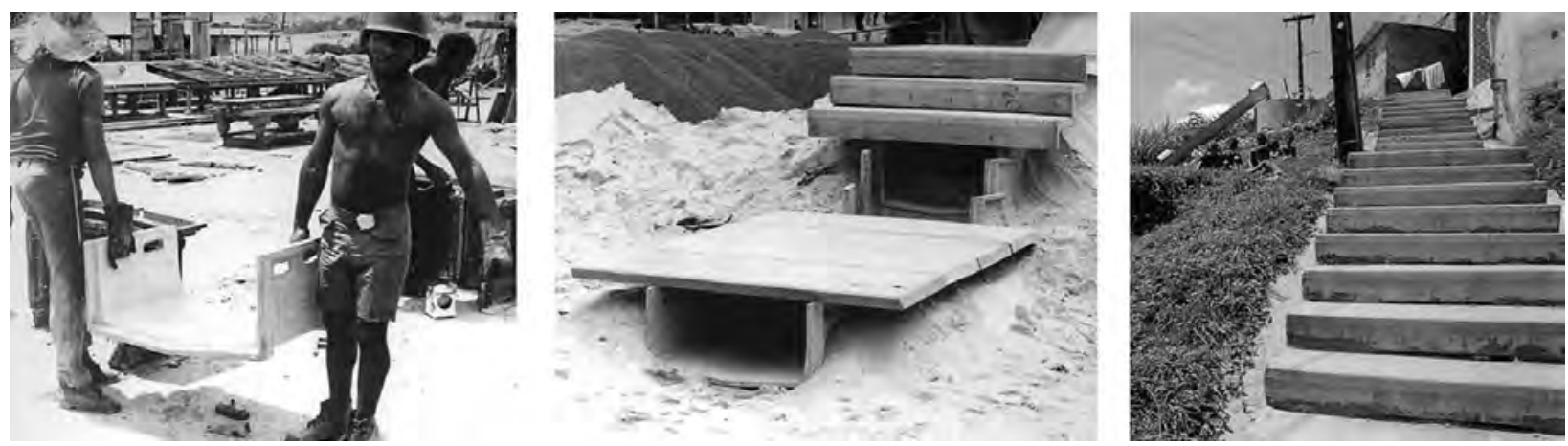

Fuente: Carvalho, Marcelo, 2000. 
FIGURA 10. SISTEMA TABIBLOC. PROPUESTA DEL CONCURSO PREVI-LIMA, AROUITECTOS ÍÑIGUEZ DE OZOÑO Y VÁZOUEZ DE CASTRO.

Pilares
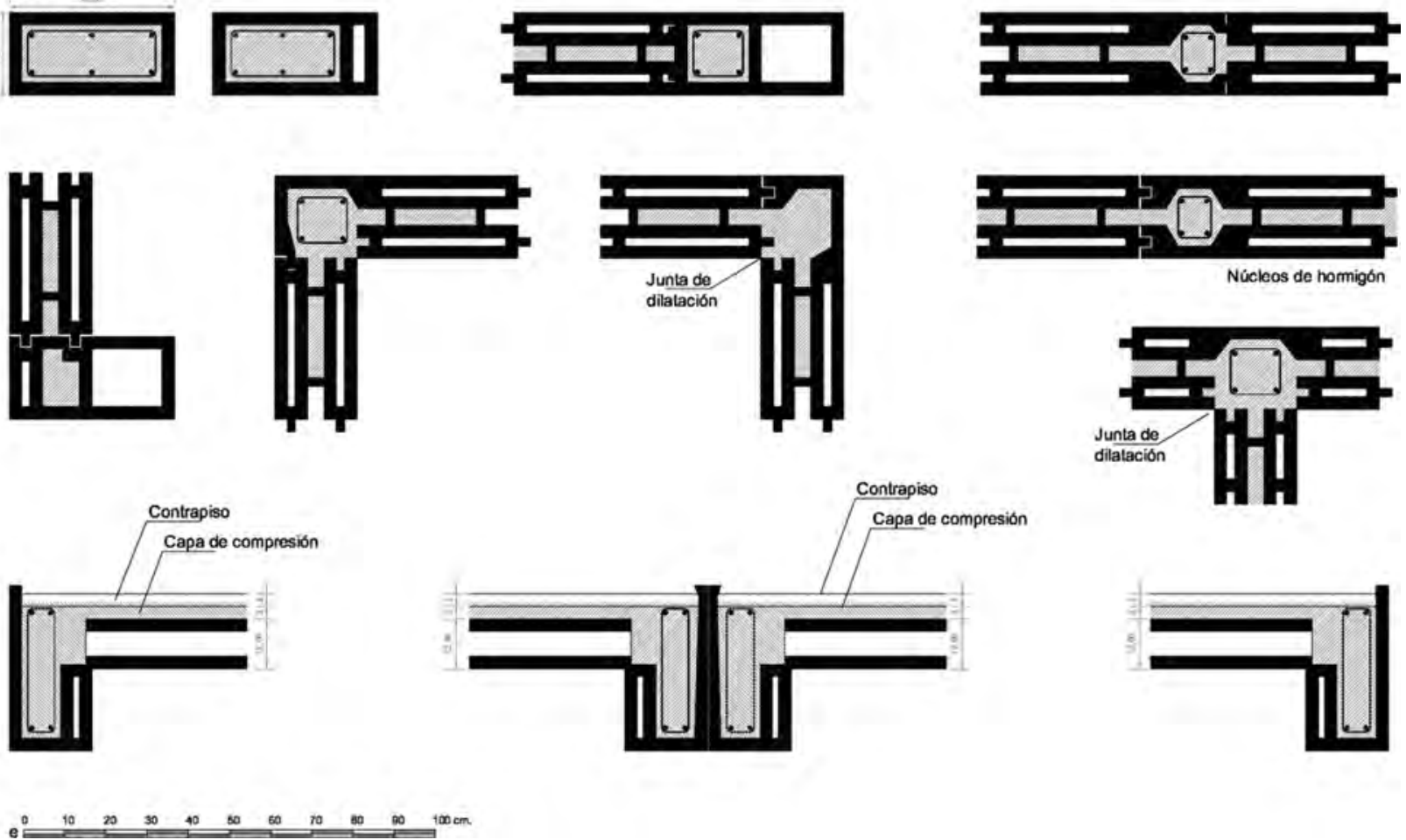

Fuente: dibujos de los autores a partir de ININVI, 1988 
más decorativos que funcionales, acordes con gustos locales, también parece de interés mencionar la variadísima producción y lograda calidad de producción de celosías y elementos prefabricados decorativos de encargo de una pléyade de talleres centroamericanos. El caso de la región de Yucatán es realmente singular (Figuras 6 y 7 ).

En cuanto a las tecnologías de producción se pueden diferenciar dos grandes grupos, la ejecución de viviendas in situ y la producción parcial en taller. En el primer caso, más cercano a la forma tradicional de construir, la producción se organiza alrededor del objeto. En el segundo, con cierto grado de industrialización y racionalización, se producen elementos que luego se montarán en el lugar de la construcción. En cualquier caso, y a pesar de las múltiples variantes, parece posible establecer una serie de criterios y recomendaciones generales para la construcción social del hábitat en los tres campos señalados: diseño, construcción y producción de la vivienda (Tabla 5).

\section{Tecnologías compatibles: algunos casos latinoamericanos}

Como se ha ido viendo, en el ámbito latinoamericano existe la necesidad de intervenir y mejorar los asentamientos humanos y existe también un

170 revista invi № 76 / Noviembre 2012 / Volumen № 27: 147-175 incipiente tejido de redes tecnológicas. Quizá sea el momento de señalar las capacidades de entidades o de profesionales en esta línea. Se trata de realizaciones que, partiendo de componentes neutros, reales y asequibles, por acople o ensamble sencillo, ofrecen soluciones tecnificadas, capaces de convertirse en prácticas de referencia para la construcción del hábitat popular en el entorno latinoamericano.

Uno de los elementos constructivos que quizá ejemplifica de manera más clara lo que es un componente neutro podría ser la ventana de hormigón desarrollada por el CEVE. Se trata de una carpintería modular ejecutada como una pieza prefabricada, que por sus características mecánicas autoportantes no requiere de ningún tipo de dintel o cargadero cuando se instala en obra. El hormigón la hace compatible con la gran variedad de cerramientos que es posible encontrarse en las construcciones informales y, a la vez, la convierte en un elemento acabado, que no requiere de pinturas, barnices u otros tratamientos posteriores. Se trata de un elemento prefabricado, pero que no necesita de un proceso industrial sofisticado, ya que las piezas pueden producirse bajo pedido en pequeños moldes unitarios. La variedad de situaciones, combinaciones y utilizaciones en las que es posible encontrar la pieza evidencian su carácter compatible (Figura 8).

Se trata de un empleo del hormigón en cierto modo similar al realizado por João Filgueiras Lima, Lelé, en el proyecto de saneamiento urbano en Salvador

ARTÍCULO: Utilización de componentes neutros de construcción en Latinoamérica / Julián Salas Serrano, Aurelio Ferrero y Patricia Lucas Alonso 
de Bahía entre los años 1980 y $1982^{27}$. En ese caso, se prefabricaban una serie de elementos de argamasa armada capaces de conformar, por agregación, una escalera que de manera simultánea facilitaba la accesibilidad en barrios populares en pendiente y servía como elemento de recolección y canalización de las aguas servidas (Figura 9).

Del componente neutro resulta relativamente fácil evolucionar al juego de piezas con sus reglas de montaje capaz de dar forma a distintos proyectos. Podríamos hablar en estos casos de sistemas versátiles. Es el caso del sistema UMA de estructura metálica. Se compone de vigas en celosía, unidas mediante cabezales abulonados, que permiten un rápido montaje, que hace posible levantar la estructura de una pequeña vivienda unifamiliar prácticamente en un solo día. El diseño del cabezal de unión permite el montaje rápido de una estructura capaz de cerrarse con múltiples acabados (Figura 4).

Frente a la industrialización pesada, cuyos genes tecnológicos ${ }^{28}$ tratan de resolver problemas netamente europeos de una determinada época, estos sistemas de prefabricación sutil ${ }^{29}$ son un camino tecnológico con cierta tradición en la construcción del hábitat popular latinoamericano.

$\begin{array}{ll}27 & \text { Carvalho, } 2000 . \\ 28 & \text { Reddy, } 1998 . \\ 29 & \text { Salas, } 2000 .\end{array}$

Junto a los sistemas ya citados, podemos mencionar también el Sandino (Cuba), el Bloque-Panel (Costa Rica) o el Sancocho (Venezuela), junto a otros sistemas recopilados por Pedro Lorenzo ${ }^{30}$ o por Héctor Massuh $^{31}$ en el marco de proyectos CYTED. También estarían dentro de este ámbito algunas de las propuestas tecnológicas del concurso de vivienda PREVI-Lima, realizado en los años setenta en el que, entre otras tecnologías, se empleó el Tabibloc de Vázquez de Castro (Figura 10).

\section{A modo de conclusiones y prospectiva}

El sector de la construcción, y de forma muy particular el de las soluciones para la realización de viviendas mínimas ex-novo, de ampliación y/o mejora de tugurios (objetivos prioritarios del presente trabajo), se muestra en gran parte retardatorio y con síntomas de permanecer claramente anclado en el pasado. La realidad tecnológica contrasta con el nivel teórico y las abundantes reflexiones sobre la producción social del hábitat ${ }^{32}$ en América Latina, y hace evidente la necesidad de llevar a la práctica nuevas opciones y propuestas tangibles.

\footnotetext{
30 Lorenzo, 2005. Una buena muestra de estos sistemas se ha recopilado también en la exposición Con o Sin Techo, promovida por la Federación Iberoamericana de Urbanistas con la colaboración de Arquitectos Sin Fronteras, Madrid, 2012.

31 Massuh, 2009.

32 Pipa; Peyloubet, y de Salvo, 2009.
} 
El continuo aumento de la población latinoamericana (con tasa de crecimiento de 1,3\% anual), aunque lejos de lo que ocurre en África (tasa de 2,1\%), resulta muy superior al resto de los continentes. Se prevé que alcance los 631 millones de habitantes en 2015. Este fenómeno requiere y propicia mayores ritmos de construcción, que sean a la vez capaces de reactivar la abundante mano de obra cesante o semiempleada, un grupo de población que además está en gran parte necesitado de soluciones habitacionales. Por otro lado, se constata el crecimiento del subsector de producción de materiales y elementos al que, en parte, se dedica este trabajo. Se trata de componentes neutros, que tienen como principales destinatarios a los usuarios con escasas capacidades adquisitivas. Ambas características propician la construcción mediante el empleo de mano de obra abundante y procesos de producción selectivos en bienes de capital, bienes que en este momento, y dado el desarrollo tecnológico local, no se entendería que fuesen importados, como se ha defendido en varios momentos de este trabajo. Una muestra de ello, son los ejemplos recopilados.

Es preciso considerar la interacción de diversos factores a la hora de abordar la compleja cuestión de los asentamientos informales que se encuentran en las periferias de buena parte de las ciudades latinoamericanas, ubicados muchas veces en lugares recónditos, que en ocasiones no permiten el acceso de grúas o de máquinas pesadas. La gestión urbana y el planeamiento se relacionan con aspectos técnicos como las infraestructuras, pero a la vez los planes y ayudas públicas conviven con multitud de pequeñas iniciativas particulares de construcción, ampliación o mejora de viviendas.

Por ello, a la hora de pensar en tecnologías posibles, es preciso pensar el problema a distintas escalas. El urbanismo y las infraestructuras requerirán sin duda una visión territorial, pero a la vez parece posible pensar en las tecnologías que pueden ayudar a dar respuesta a las demandas de pequeñas acciones. Ampliaciones, reformas, consolidaciones... muchas y variadas, son las iniciativas que los propios habitantes emprenden con la intención de mejorar las características físicas de su entorno. Pensar en tecnologías sencillas, que se puedan producir en series cortas capaces de adaptarse a múltiples entornos y que a la vez ofrezcan mejores prestaciones que los métodos tradicionales, parece una opción viable de trabajo.

La implantación de la financiación por microcréditos o microsubsidios contribuye al proyecto de este tipo de elementos que constituyen soluciones parciales pero completas. Completas, porque suponen el proyecto de un elemento que no requiere acabados posteriores, y parciales, porque dejan de lado la idea del prototipo y de la unidad de vivienda terminada, para ofrecer un elemento agregable, una mejora o una ampliación de lo que ya existe, a lo que no sustituyen, sino que complementan. 
Este tipo de elementos y componentes se ofrecerían a los usuarios minoristas como una posibilidad de mejora en el tiempo. Resulta difícil pensar que el sector privado y formal, que emplea técnicas tradicionales de construcción, vaya a emplear estos componentes de manera masiva. Sin embargo, sí parece viable plantear su empleo a gran escala por todos aquellos pequeños constructores que amplían, mejoran o reparan sus viviendas. El fomento de este tipo de elementos y sistemas estaría buscando en este caso una rentabilidad social.

Al pensar en este tipo de sistemas surge también la cuestión de cómo poner en marcha el proceso. En la realidad social de América Latina es posible encontrar ya la necesaria red de pequeños productores y autoconstructores. Además del financiamiento, sería necesario incidir ahora en la difusión de este tipo de sistemas. Es aquí donde adquieren especial relieve las tareas de recopilación de datos, divulgación y transferencia de conocimiento; así como catalogar los procesos de fabricación, ejecución y sus distintas aplicaciones.

El trabajo con este tipo de elementos puede contribuir a dotar de mejores características técnicas a las construcciones surgidas de las iniciativas particulares de los propios habitantes, ayudando a la consolidación de los barrios gracias a la acción progresiva. Pueden ayudar a mejorar el conjunto a través de la suma de acciones particulares. Se trataría del reflejo tecnológico de los sistemas micro que, sin embargo, han de interactuar con lo macro: con la planificación urbana, el acceso al suelo, la intervención en las infraestructuras y la acción pública.

Los componentes neutros, por sí solos, no van a solventar los retos que plantean estas cuestiones. No obstante, las tecnologías compatibles presentan un alto potencial de capacidad para contribuir a la consolidación de los asentamientos informales. Se trata de acciones que, a la vez, deben acompañarse de operaciones estructurales en el terreno de las infraestructuras y del planeamiento urbano. Los componentes neutros no son la respuesta, sino una posible vía, entre todas las necesarias, para abordar tan amplio y complejo problema.

\section{Bibliografía}

ABRAM0, Pedro. La teoría económica de la favela: cuatro notas sobre la localización residencial de los pobres y el mercado inmobiliario informal. Ciudad y Territorios: Estudios territoriales. (136137): 273-294, 2003. ISSN 1133-4762.

Bosío, Cristina y GARCíA, Damián. Micro-créditos: estrategias, realizaciones, perspectivas. [En línea]. Revista INVI. 22(61): 31-42, noviembre 2007. ISSN 0718-8358. Disponible en: http://revistainvi. uchile.cl/index.php/INVI/article/view/275/932.

BUTHET, Carlos; BAIMA DE BORRI, Marta y CALVO, Diego. La evolución de las villas de emergencia en Córdoba 2001/ 2007. Córdoba, Argentina, Servicio Habitacional y de Acción Social. 2007.

revista invi № 76 / Noviembre 2012 / Volumen № 27: 147-175 173 
CARVALHO, Marcelo, coord. João Filgueiras Lima Lelé. Lisboa, Portugal, Blau. 2000. 264 p. ISBN 972-8311-49-4

CEPAL. Instrumentos financieros para mejorar el acceso a la vivienda de los sectores de menores ingresos en América Latina y el Caribe. Montevideo, Uruguay, CEPAL. 2006. 31 p.

CEPAL. La producción de la vivienda en América Latina y El Caribe. Santiago de Chile, CEPAL. 1996. 285 p.

CILENTO SARLI, Alfredo. Los enfoques tecnológicos del IDEC: del desarrollo de sistemas constructivos a la sostenibilidad de la construcción. En: CALVO, Azier, coord. Facultad de Arquitectura y Urbanismo UCV 1953-2003. Aportes para una memoria y cuenta. Caracas, Venezuela, Ediciones FAU/UCV. 2005, ISSN 0798-9601.

FERNÁNDEZ WAGNER, Raúl. La construcción y deconstrucción histórica de lo social en el acceso a los bienes y servicios del hábitat. [En línea]. Revista INVI. 19(50): 11-20, mayo 2004. ISSN 07188358. Disponible en: http://revistainvi.uchile.cl/ index.php/INVI/article/view/355/857.

FERRERO, Aurelio y BASSO, Laura. Progresividad habitacional: del reconocimiento a la propuesta. Cuaderno Urbano. 7(7): 145-163, octubre 2008. ISSN: 1666-6186.

FERRER0, Aurelio, coord. Hábitat en Riesgo. Experiencias latinoamericanas. Córdoba, Argentina, CYTED, Subprograma XIV Tecnologías de vivienda de interés social, Red XIV-G. 2003. 215 p. ISBN 987-21050-0-6.

174 revista invi № 76 / Noviembre 2012 / Volumen N ํ2 27: 147-175
GONZÁLEZ LOBO, Carlos. Vivienda y ciudad posibles. Bogotá, Colombia, Escala. 1999. 229 p.

ININVI. PREVI 20 años después: resultados y conclusiones. Lima, Perú, Secretaría Ejecutiva del Programa de Actividades PREVI '88. 1988. 40 p.

LORENZO GÁLLIGO, Pedro, coord. Un techo para vivir. Tecnologías para viviendas de producción social en América Latina. Barcelona, España, Edicions UPC, CYTED, subprograma XIV, proyecto XIV.3 y XIV.5. 2005. 559 p. ISBN 84-8301-801-2.

MASSUH, Héctor; NAVILLI, Norma; BAREA, Germán Augusto y O'NEILL, Arturo Jorge, coords. Hacia las tecnologías apropiadas en viviendas de interés social en Latinoamérica. Córdoba, Argentina, CYTED, Proyecto XIV-8. 2009.

PIPA, Dante; PEYLOUBET, Paula y de SALVO, Laura, coords. Ciencia y tecnología para el hábitat popular: desarrollo tecnológico alternativo para la producción social de hábitat. Buenos Aires, Argentina, Nobuko. 2009. 400 p. ISBN 978-987-584-187-1.

RAMÍREZ, Ronaldo. Evaluación social de políticas y programas de vivienda: un análisis de la contribución de la vivienda. [En línea]. Boletín INVI. 17(45): 9-57, mayo 2002. ISSN: 0716-5668. Disponible en: http://revistainvi.uchile.cl/index.php/ INVI/article/view/380/823.

REBORD, Gustavo. Irregularidad en la tenencia de la propiedad. Hoy la Universidad, Revista de la Universidad Nacional de Córdoba. 2(3): 42-44, junio 2010. ISSN: 1667-6289.

ARTÍCULO: Utilización de componentes neutros de construcción en Latinoamérica / Julián Salas Serrano, Aurelio Ferrero y Patricia Lucas Alonso 
REDDY, Amulya Kumar. Background and concept of appropriate technology. En: Conferencia UNIDO,(1998, Nueva Delhi, India).

ROMERO, Gustavo. La vivienda evolutiva y el diseño. En: JORNADAS iberoamericanas sobre hábitat evolutivo y producción social del hábitat: tecnologías y herramientas de apoyo, CYTED y AECI (2006, Cartagena de Indias, Colombia).

SALAS, Julián et al. Las tomas de tierras urbanas en Latinoamérica: problema o solución. Madrid, España, Ministerio de Vivienda. 2010. 247 p. ISBN 978-84-96387-48-5.

SALAS, Julián. Tugurización y necesidades de habitabilidad básica, rémoras de la cohesión social en Latinoamérica. [En línea]. Pensamiento Iberoamericano. (1): 207-230, 2007. ISSN 0212-0208. Disponible en: http://www.pensamientoiberoamericano.org/articulos/1/47/0/tugurizaci-n-y-necesidades-de-la-habitabilidad-b-sica-en-latinoamrica-r-moras-a-la-cohesi-n-social.html.
SALAS, Julián. La industrialización posible de la vivienda latinoamericana. Bogotá, Colombia, Escala. 2000. 275 p. ISBN 958-9082-96-3.

SALAS, Julián; SALAZAR, Guadalupe y PEÑA, Magda. Una propuesta esquemática para el análisis de la autoconstrucción en Latinoamérica como fenómeno masivo y plural. [En línea]. Informes de la construcción. 40(398): 155-168, 1988. ISSN 0020-0883. Disponible en: http:// informesdelaconstruccion.revistas.csic.es/index.php/informesdelaconstruccion/article/ view/1584/2398.

SEPÚLVEDA, Rubén; de la PUENTE LAFOY, Patricio; TORRES ROJAS, Emilio y MUÑOZ SALAZAR, Patricia. Progresividad residencial: un estudio socio-físico del Programa de Mejoramiento de Barrios. Santiago, Chile, Instituto de la Vivienda Facultad de Arquitectura y Urbanismo. 1994. 212 p. ISBN: 956-19-0195-1. 